\title{
ВОПРОСЫ ОБЕСПЕЧЕНИЯ ЭНЕРГЕТИЧЕСКОЙ БЕЗОПАСНОСТИ КЫРГЫЗСКОЙ РЕСПУБЛИКИ В УСЛОВИЯХ ЕВРАЗИЙСКОГО ЭКОНОМИЧЕСКОГО СОЮЗА
}

\author{
В.М. Касымова, А.В. Архангельская \\ Кыргызский государственный технический университет \\ им. И. Раззакова, Бишкек, Кыргызская Республика, \\ e-mail:valentinakasymova@gmail.com,a_ann@mail.ru
}

Со времени обретения независимости в энергетике Кыргызской Республики накопился ряд кризисных явлений, создающих угрозу энергетической безопасности страны. Помимо высокой степени износа основных фондов энергокомпаний, высокого уровня задолженности перед кредиторами, на сегодняшний день республика существенно отстает от других постсоветских стран как в сфере наращивания энергетических мощностей, так и организации процесса мониторинга состояния энергетической безопасности для принятия своевременных управленческих решений. Цель данного исследования заключается в рассмотрении сущности факторов и угроз энергетической безопасности, их оценке на примере Кыргызской Республики. Вступление Кыргызской Республики в Евразийский Экономический союз оказало влияние на состояние и перспективы обеспечения энергетической безопасности Кыргызской Республики с учетом формирования единых рынков электроэнергии, газа, нефти и нефтепродуктов, главным образом за счет воздействия на внешние факторы энергетической безопасности.

Ключевые слова: энергетическая безопасность, внешние и внутренние угрозы, электроэнергетика, рынок, тариф на электроэнергию.

\section{THE MATERS OF THE ENERGY SECURITY OF THE KYRGYZ REPUBLIC IN THE CONDITIONS OF THE EURASIAN ECONOMIC UNION}

\section{V.M. Kasymova, A.V. Arkhangelskaya}

\section{Kyrgyz State Technical University named after I. Razzakov, Bishkek, Kyrgyz Republic,} e-mail:valentinakasymova@gmail.com,a_ann@mail.ru

Since independence, the energy sector of the Kyrgyz Republic has accumulated a number of crisis phenomena that pose a threat to the country's energy security. 
In addition to the high degree of depreciation of fixed assets of energy companies, a high level of debt to creditors, today the republic lags significantly behind other post-Soviet countries both in increasing energy capacities and organizing the process of monitoring the state of energy security for making timely management decisions. The purpose of this study is to examine the nature of the factors and threats to energy security, their assessment on the example of the Kyrgyz Republic. The entry of the Kyrgyz Republic into the Eurasian Economic Union influenced the state and prospects of ensuring the energy security of the Kyrgyz Republic, taking into account the formation of unified electricity, gas, oil and petroleum products markets, mainly due to the impact on external factors of energy security.

Keywords: energy security, external and internal threats, electric power industry, market, electricity tariff.

\section{Введение}

Топливно-энергетический комплекс (ТЭК) - один из фундаментов экономик стран Евразийского экономического союза (ЕАЭС), которые обладают значительными запасами ресурсов. С энергетической точки зрения ЕАЭС - это: 20\% мировых запасов природного газа и более 50\% мирового экспорта; более $20 \%$ запасов угля и 4,9\% мировой добычи; 7,8\% мировых запасов нефти, 14,2\% мировой добычи и $18 \%$ мирового экспорта; 5,1\% мирового производства электроэнергии. ТЭК в ЕАЭС - это: 20\% внутреннего валового продукта; более трети промышленного производства.

В настоящее время в ЕАЭС реализуется масштабный проект со сроком реализации до 2025 г. по поэтапному формированию общих рынков энергетических ресурсов (электроэнергии, газа, нефти и нефтепродуктов) на основе соответствующих концепций, программ и международных договоров.

Сдерживание начала работы общих рынков энергоресурсов неблагоприятно влияет на состояние энергетической безопасности стран союза, особенно Кыргызской Республики (КР).

Проблема энергетической безопасности возникла в КР, как и в других постсоветских странах, со времени установления независимости государства.

За годы независимости получили развитие негативные тенденции состояния энергетической безопасности страны. Резко снизилось энергопотребление промышленных потребителей, в энергетической отрасли не вкладывались средства в обновление и модернизацию оборудования, что привело к его старению, аварийности и снижению эксплуатационной готовности. Наблюдаются и другие негативные процессы, которые болезненно отражаются на экономике в целом, сдерживают рост ее показателей и не благоприятствуют повышению жизненного уровня населения. Все более острыми становятся вопросы доступного и надежного энергоснабжения отраслей экономики и населения, а также обеспечение устойчивой работы самого энергокомплекса. Весь комплекс этих вопросов обусловил возникновение проблемы обеспечения энергетической безопасности республики. 


\section{Обзор литературы}

Исследования проблем обеспечения энергетической безопасности связаны с ситуациями воздействий на энергетику различного рода факторов и угроз, так как в этих случаях существует реальная опасность дестабилизации энергоснабжения реального сектора экономики и населения.

Вопросы энергетической безопасности, включая анализ факторов и угроз, индикативный анализ состояния энергетической безопасности и другие рассматриваются в трудах ученых КР В.М. Касымовой, Б.И. Баетова, А.В. Архангельской (Баетов, 2010; Баетов Б.И., Архангельская, 2018; Касымова, 2017; Касымова, Архангельская, Куржумбаева, 2017).

Определения угрозы энергетической безопасности приводятся в трудах В.В. Бушуева, А.М. Мастепанова, П.И. Родионова как совокупность условий и факторов, создающих экстремальные ситуации в системах топливои энергоснабжения потребителей, представляющих опасность для нормального функционирования этих систем, а значит, и жизненно важных интересов личности, общества и государства (Бушуев, 2006).

На конкретные угрозы энергетической безопасности влияют экономические, социально-политические, техногенные и природные факторы.

Экономические угрозы включают: широкомасштабные неплатежи и дефицит инвестиционных ресурсов, что является причинами недостаточного ввода новых мощностей; низкие темпы реконструкции и технического перевооружения в отраслях ТЭК; неприемлемое снижение резерва мощностей; старение и износ основных средств и производственного аппарата; финансовая дестабилизация в отраслях ТЭК из-за кризиса неплатежей; высокий уровень энергоемкости экономики и снижение конкурентоспособности продукции; слабость экономических стимулов к насыщению внутреннего рынка энергоносителей и другие.

Социально-политические угрозы включают национальные и региональные конфликты, сопровождаемые военными действиями вблизи объектов ТЭК; социальную напряженность (забастовки, движения за снижение высоких цен и тарифов на энергоносители и др.); дискриминационные меры внешних торговых партнеров; невыполнение международных конвенций и соглашений по минимизации воздействия ТЭК на окружающую среду и др.

Угрозы техногенного характера: быстро нарастающий в отраслях ТЭК удельный вес морально устаревших и физически изношенных основных средств и оборудования; низкий уровень природоохранной деятельности и экологической безопасности в отраслях ТЭК; снижение научно-технического потенциала в ТЭК из-за недостаточного финансирования науки.

Природными или экологическими угрозами энергетической безопасности страны являются истощение природных ресурсов; стихийные бедствия; климатические (аномальные проявления естественных природных процессов, суровые зимы, маловодность речного стока, приводящие к локальным или массовым напряженностям в энергобалансе). 
При этом всегда с позиций интересов конкретного потребителя, страны (КР) или Центрально-Азиатского региона (ЦА) можно говорить о внешних и внутренних угрозах энергетической безопасности.

Основными факторами, влияющими на устойчивость и надежность функционирования ТЭК и на энергетическую безопасность страны в целом, являются следующие:

1) устойчивое финансово-экономическое положение отраслей комплекса;

2) достаточность их инвестиционного потенциала;

3) состояние и технический уровень основных производственных фондов;

4) развитие и подготовленность сырьевой базы ТЭК;

5) региональная энергетическая сбалансированность;

6) достаточность резервов энергетических мощностей, топливных ресурсов и энерготранспортных коммуникаций;

7) повышение эффективности энергоиспользования и экономически обоснованная минимизация энергоемкости экономики;

8) подготовленность ТЭК к функционированию в экстремальных ситуациях.

Очевидно, что эти основные составляющие всего комплекса проблем энергетической безопасности в условиях рыночной экономики в той или иной мере будут формироваться под воздействием рыночных рычагов и механизмов, однако обеспечить гарантированное достижение их необходимого уровня невозможно без мер государственной поддержки, регулирования и даже контроля на соответствующей законодательной основе (Шамраев, Троицкий, 1996).

Развал единого союзного государства и последующий за этим процесс постепенного разделения энергосистем каждой суверенной республики в отдельные энергетические компании по производству, передаче и распределению электро- и теплоэнергии еще более усложнили решение этой важной задачи. Желание ускоренного перехода к рыночным взаимоотношениям и максимального использования финансовой поддержки международных доноров привело к серии ошибок, которые за весьма короткое время подвели отрасль к предкризисной черте.

Действия по обеспечению, укреплению энергетической безопасности могут либо носить характер мероприятий непосредственно по ликвидации и предотвращению кризисных ситуаций, либо обеспечиваться преимущественно путем реализации решений по развитию и функционированию ТЭК, систем энергетики, энергетических объектов и потребительского сектора, принятых с учетом фактора экономической безопасности.

В подавляющем большинстве задачи обоснования и выбора хозяйственных, экономических, социальных решений являются многокритериальными. Это относится к решениям как хозяйствующих субъектов, так и государственных органов; к задачам, решаемым на разных территориальных уровнях и с разной степенью заблаговременности; к задачам управления как развитием, так и функционированием предприятий, отраслей, экономики в целом.

Определенное место среди применяемого при этом множества критериев 
должны занимать критерии наилучшего соответствия требованиям отдельных видов безопасности.

Применительно к задачам развития ТЭК и его составляющих, отчасти и к задачам энергопотребляющих компонентов экономики, фактор энергетической безопасности должен быть одним из основных критериев принятия решений, наряду с критериями экологичности, энергоэффективности, окупаемости инвестиций, производительности труда, надежности, производственной безопасности, качества продукции и др.

Энергетическая безопасность является минимально необходимым условием функционирования и стратегического развития топливно-энергетической сферы, а также всей социально-экономической политики государства.

Несоблюдение этого условия приводит не только к угрозе энергетического кризиса, но и, в силу высокой зависимости всей страны от энергетического фактора, к угрозе ее национальной безопасности.

Академиком В.В. Бушуевым разработаны следующие принципы по защите от угроз энергетической безопасности (Бушуев, 2006: 200):

1) заменимость исчерпаемого ресурса, при этом темпы потребления исчерпаемых ресурсов топлива не должны превышать темпы освоения замещающих их источников энергии;

2) диверсификация видов топлива и энергии (экономика не должна чрезмерно зависеть от какого-либо энергоносителя);

3) рациональное потребление органических видов топлива;

4) приоритетность внутреннего потребления энергоресурсов по отношению к их экспорту и рационализация структуры экспорта;

5) государственная поддержка инвестиционных проектов в ТЭК, привлекающих в страну инвестиции, и создание новых рабочих мест.

Деятельность государства, по предложениям российских ученых Г.С. Асланяна, С.Д. Молодцова, А.А. Соловьянова (2001), ориентированная на поддержание и укрепление энергетической безопасности, должна осуществляться по следующим основным направлениям:

1) определение приоритетов развития энергетики и планирование перспективных потребностей в ТЭР;

2) решение вопросов, связанных с национализацией и приватизацией собственности, включая контроль и регулирование уровня зарубежной собственности;

3) поддержание финансовой стабильности энергетического сектора и привлечение в его отрасли дополнительных инвестиций за счет разработки и применения гибкой и работоспособной нормативно-правовой базы и финансово-налоговой системы, учитывающей особенности ценообразования и взаимоотношений энергетики со смежными отраслями;

4) формирование и реализация стратегической линии поведения на мировых энергетических рынках и рынках энерготехнологий, а также политики взаимоотношений со странами, через территорию которых пролегают энерготранспортные артерии; 
5) формирование, контроль и регулирование уровня стратегических запасов ТЭР;

6) регулирование внутреннего спроса на энергоносители через энергосберегающие мероприятия;

7) поддержка, включая меры протекционистского характера, убыточных либо стратегически важных отраслей энергетики, а также развития новых перспективных энергоэффективных технологий.

\section{Гипотеза и методы исследования}

Гипотеза исследования заключалась в том, что вхождение КР в ЕАЭС оказало положительное влияние на перспективы обеспечения энергетической безопасности КР за счет создания единых рынков электроэнергии, газа, нефти и нефтепродуктов.

Эмпирическую базу исследования составили результаты применения следующих методов: качественный анализ официальных отчетных данных о результатах работы предприятий ТЭК, топливно-энергетического баланса КР Национального статистического комитета КР, аналитических справок министерств и ведомств, контент-анализ печатных средств массовой информации, интервьюирование лиц, принимающих решения. Использование качественного анализа документов позволило провести оценку внешних и внутренних угроз энергетической безопасности страны. Использованы документы, отражающие развитие энергетических предприятий в период с 1999 по 2018 г. Всего было исследовано более 30 документов: 1) официальные документы: нормативно-распорядительные документы предприятий ТЭК и уполномоченных государственных органов в сфере энергетики (приказы, постановления, распоряжения), годовые отчеты по различным направлениям деятельности, статистические справки, положения, стратегия развития; 2) неофициальные документы: рабочие материалы Государственного комитета промышленности, энергетики и недропользования КР, Государственного агентства по регулированию ТЭК при Правительстве КР, ОАО «Национальная энергетическая холдинговая компания» и др. Метод контент-анализа позволил изучить современный опыт развития энергетики и обеспечения энергетической безопасности соседних стран. Для этого были использованы печатные средства массовой информации, которые публикуются на выбранной территории и отражают ситуацию, происходящую на ней, пользуются наибольшей популярностью среди целевой аудитории исследования (работники предприятий ТЭК, эксперты и НПО в сфере энергетики).

Интервьюирование проводилось в ноябре-декабре 2018 г. среди сотрудников министерств и ведомств в сфере энергетики и ЕАЭС. Объем выборочной совокупности - 30 человек. Основная цель опроса — выявить представления работников о состоянии энергетической безопасности страны, результатах и перспективах его изменения с учетом пребывания в ЕАЭС. Применялась программа STATA и методы математической статистики (корреляционный и факторный анализ).

\section{Результаты исследования}

Анализ внутренних угроз энергетической безопасности показал следующую ситуацию. 
Обладая достаточным потенциалом топливно-энергетических ресурсов (ТЭР), области и страна в целом не в состоянии обеспечить полностью свою энергетическую безопасность из-за следующих факторов: неравномерность размещения ТЭР по территории, низкий уровень освоенности ТЭР, опережение темпов роста спроса на энергоносители над их предложением и зависимость производства электроэнергии больших и малых ГЭС от природно-климатических условий; импорта природного газа, нефти и нефтепродуктов из России, частично угля из Республики Казахстан и закупочных цен на них, связанных с колебаниями мировых цен на углеводородное топливо.

В угольной отрасли: износ оборудования недостаток оборотных средств, высокая дебиторская задолженность потребителей негативно влияют на качество ремонтных работ горной техники, состояние автодорог, своевременность проведения вскрышных работ для подготовки фронта добычи угля.

В сфере газоснабжения наблюдается отставание реализации Генеральной схемы газоснабжения и газификации КР на период до 2030 г. и Инвестиционной программы OcOO «Газпром Кыргызстана», в результате отсутствует возможность подключения к газоснабжению абонентов в запланированные сроки.

В электроэнергетике наблюдается опережение темпов роста спроса на энергоносители над их предложением и отсутствие резерва мощности, зависимость производства электроэнергии больших и малых ГЭС от природно-климатических условий.

Ввод новых мощностей отстает от темпов роста нагрузки в энергосистеме, так как за последние десять лет был введен в действие только один агрегат на 120 МВТ Камбаратинской ГЭС-2.

Износ основных фондов электрических станций достиг 70-93\% (при кризисном пороге 25\%), с превышением нормативов сроков эксплуатации (25-30 лет).

Сохраняются высокие потери электроэнергии по сетям высокого напряжения - 5,49\% по итогам 2017 г., обусловленные высоким коэффициентом износа электрических сетей, превышением сроков службы трансформаторов на подстанциях, приборов измерения и учета электроэнергии, что является причиной аварий и отключений при повышении нагрузки.

В сфере распределения электроэнергии проблемами остаются превышение уровня потерь 10\%-го порога, перегрузки электрических сетей и подстанций в зимнее время, особенно в районах новостроек, и связанная с этим социальная напряженность среди населения.

Проведение социально-ориентировнной тарифной политики привело к зависимости деятельности энергокомпаний от долгосрочных заемных средств и сокращению собственных средств на развитие. По состоянию на 1 января 2019 г. по заключенным кредитным соглашениям в рамках реализации инвестиционных проектов предприятиям ТЭК необходимо выплатить порядка 102,5 млрд сом.

В связи с существующими трудностями по соблюдению графиков погашения задолженности электроэнергетическими компаниями и с дефицитом денежных средств периодически проводится реструктуризация задолженности по государ- 
ственным заемным средствам. За 2010-2016 гг. проведена реструктуризация задолженности на сумму 1,41 млрд сом, а также выделены бюджетные ссуды на сумму 7,7 млрд сом.

При таком финансовом положении энергокомпаний дальнейшее увеличение долговой нагрузки при существующих тарифах неприемлемо. Имея огромные долги, страна может потерять контроль над стратегически важной отраслью, так как кредиторы за долги могут потребовать продажи ОАО «Национальная энергетическая холдинговая компания» со всеми дочерними энергокомпаниями, и тогда Правительство КР не сможет вести политику сдерживания роста тарифов на электро- и теплоэнергию, исходя из социального положения населения. Поскольку объекты электроэнергетики становятся залоговым имуществом при получении кредитов, следует констатировать тот факт, что угроза энергобезопасности и сохранению энергонезависимости из года в год растет и обостряется.

Полученные результаты свидетельствуют о том, что у компаний электроэнергетики показатели финансовой деятельности неутешительные и ситуация усугубляется из года в год. Стремительно растут долговые обязательства, собственные средства сокращаются. Назрела необходимость ввода моратория на заем средств, консолидации имеющихся в наличии средств по всей отрасли и осуществления точечного финансового оздоровления по компаниям в зависимости от выявленных очагов кризиса с помощью механизма диагностирования.

Для финансового оздоровления предприятий энергетики необходимо: сократить все непроизводительные расходы, и в первую очередь излишние структуры управления, - это ОАО «Национальная энергетическая холдинговая компания», затраты на содержание которого ложатся на потребителей электро- и теплоэнергии. Необходимо привести все расходы к нормативам.

Государственное агентство по регулированию ТЭК при Правительстве КР должно быть независимым регулятивным органом, обладать полномочиями проводить независимую тарифную политику и информировать общественность о реальных затратах энергетических компаний и обоснование устанавливаемых тарифов на электрическую и тепловую энергию, а также природный газ. На сегодня потребители не обладают достаточной информацией, в связи с чем и растет недовольство при малейшем намеке о повышении тарифов на них.

Анализ существующей ситуации с использованием возобновляемых источников энергии показывает, что с принятием Закона КР «О возобновляемых источниках энергии» в 2008 г. существенных изменений не произошло, за исключением введения в эксплуатацию микро-ГЭС, биогазовых и солнечных установок по демонстрационным проектам. Освоение потенциала ВИЭ для получения электрической энергии, горячей воды и биогаза позволит аккумулировать больше энергии в водохранилищах Нижне-Нарынского каскада с последующим использованием в осенне-зимний период и сокращением ее дефицита.

В региональном разрезе проблемы энерго- и топливоснабжения весьма существенны. Не обеспеченными собственными ТЭР являются Чуйская и Таласская области. Проблемы повышения энергообеспеченности регионов КР необходимо 
срочно решать за счет разработки местных месторождений угля; проведения энергосберегающей политики малозатратными методами, повышения энергоэффективности производства, общественных зданий и жилых домов с сокращением выбросов ПГ; разработки мероприятий по реконструкции отопительных котельных и создания локальных систем теплоснабжения.

В настоящее время социально-экономическое развитие страны и регионов с позиций энергоэффективности является энергозатратным: сравнение индикатора энергоемкости ВВП с наилучшей международной практикой по данным Мирового энергетического агентства показывает его высокое значение - 1,1 т.н.э./1000 долл. при среднемировом значении 0,24 т.н.э./1000 долл. и 0,22-0,74 т.н.э./1000 долл. в развивающихся странах, что свидетельствует об отсутствии энергосберегающей политики.

По экологическому блоку по данным, приведенным в Третьем национальном сообщении КР по Рамочной конвенции ООН об изменении климата, утвержденным Постановлением Правительства КР от 13 октября 2016 г. № 546, наибольший вклад в эмиссию парниковых газов вносит энергетический сектор, хотя его вклад заметно уменьшается. В 1990 г. на энергетический сектор приходилось 73,3\% выбросов в $\mathrm{CO}_{2}$ эквиваленте, а к 2015 г. доля уменьшилась до 52,4\%. Уменьшилась и доля процессов сжигания ископаемого топлива в энергетическом секторе - с 95,5\% в 1990 г. до 87,4\% в 2010 г. С 2011 г. произошло снижение объемов удельных эмиссий на 1 т.н.э первичных топливных ресурсов, однако данный показатель все еще является высоким. Анализ тенденций основных климатических индикаторов показывает их неудовлетворительное состояние, что не только затрудняет выполнение обязательств КР по реализации статей Конвенции ООН по изменению климата от 9 мая 1992 г. (РКИК ООН), но и не обеспечивает устойчивое развитие, естественно подразумевающее усиление энергетической безопасности. Основные проблемы связаны в первую очередь с обеспечением энергоэффективности конечного потребления ТЭР, поскольку эмиссия ПГ как при производстве, так и потреблении ТЭР оказывает значительное влияние на их рост. Планирование и управление спросом на энергоносители требует установления пороговых значений энергопотребления через снижение темпов роста энергоемкости ВВП и, как следствие, снижение углеродоемкости ВВП.

В связи с этим необходимо предпринимать меры по обеспечению минимальных выбросов $\mathrm{CO}_{2}$ как при производстве, так и при потреблении ТЭР.

Здесь следует отметить, что пребывание КР в ЕАЭС на сегодняшний день никак не благоприятствует противостоянию внутренним угрозам энергетической безопасности ввиду затягивания процесса создания общих рынков энергоресурсов, слабой взаимной заинтересованности в обмене опытом и технологиями.

Анализ внешних угроз показал, что во внешней энергетической политике КР также потеряла свои позиции в регулировании водно-энергетических ресурсов в бассейне р. Сырдарья и в обеспечении параллельной работы энергосистем в ОЭС ЦА.

Значимость кыргызской энергосистемы со времен СССР определялась ее возможностями по экспорту электроэнергии и регулированию частоты в ОЭС ЦА, 
низкой себестоимостью и экологически чистой электроэнергией ГЭС по сравнению с электроэнергией тепловых электростанций соседних стран. Одновременно значимость ГЭС КР определялась ее возможностями накапливать и регулировать водные ресурсы.

С развалом СССР в КР продолжено накопление и осуществление пропусков воды для ирригационных нужд соседних государств. При этом КР, осуществляющая регулирование стока и подачу воды, а также строительство, эксплуатацию, содержание гидротехнических сооружений для выгод государств нижнего течения, имеет право на возмещение затрат на их содержание. Такое право заложено в Соглашении от 17 марта 1998 г. между правительствами Кыргызской Республики, Казахстана, Таджикистана и Узбекистана об использовании водно-энергетических ресурсов бассейна реки Сырдарьи, предусматривающем создание компенсационных механизмов регулирования водных ресурсов Токтогульского водохранилища. Предусматривается компенсация путем осуществления поставок в КР в эквивалентном объеме энергоресурсов (уголь, газ, топочный мазут, электроэнергия), а также другой продукции (работ, услуг), или в денежном выражении, для создания необходимых ежегодных и многолетних запасов воды в водохранилищах для ирригационных нужд. Указанное Соглашение было заключено на пять лет. В 1999 г. параллельная работа энергосистем стран ЦА была закреплена Соглашением между правительствами Кыргызской Республики, Казахстана, Таджикистана и Узбекистана о параллельной работе энергетических систем государств ЦА. Расходы на содержание Токтогульского водохранилища покрывались за счет экспорта электроэнергии по установленной цене 4 цента за кВт.ч.

С приобретением независимости республики ЦА стали ориентироваться на самообеспечение ТЭР, и в первую очередь электроэнергией.

За 2000-2017 гг. экспорт электроэнергии осуществлялся в Казахстан, КНР, Таджикистан и Узбекистан, Россию (2003-2005 гг.). Объемы экспорта зависели от приточности воды и достигнутых двухсторонних соглашений. Вместо закрепленного Соглашением от 17 марта 1998 г. между правительствами Кыргызской Республики, Казахстана, Таджикистана и Узбекистана об использовании водно-энергетических ресурсов бассейна реки Сырдарьи экспорта электроэнергии попутно с водой в объеме до 2,2 млрд кВт.ч в многоводные годы (против 7,1 млрд кВт.ч в 1990 г.) произошло его сокращение до 1,9 млрд кВт.ч в 2012 г., а в маловодье — до 860 млн кВт.ч в 2009 г. и 374,8 млн кВт.ч в 2013 г. Импорт зимней электроэнергии сократился с 3,2 млрд кВт.ч в 1990 г. до нуля к 2003 г. Однако в связи с маловодьем импорт возобновился с 2014 г. в объеме 404,8 млн кВт, в 2015 г. — 547,3 млн кВтч, в 2016 г. 133,2 млн кВт.ч, но уже по рыночным ценам. В многоводье в 2017 г. экспорт составил 1,2 млрд кВт.ч. и в 2018 г. - порядка 700 млн кВтч в Узбекистан.

Нынешняя ситуация диктует необходимость принятия решений по изменению существующей схемы взаимодействия с учетом климатических условий (чередующихся циклов маловодья и многоводья в бассейне рек Нарын - Сырдарья) и созданию в ближайшее время сбалансированной системы, отвечающей интересам всех государств, в частности возобновления сотрудничества в рамках Соглашения 
между правительствами Кыргызской Республики, Казахстана, Таджикистана и Узбекистана об использовании водно-энергетических ресурсов бассейна реки Сырдарья от 17 марта 1998 г.

\section{Выводы}

Реформирование системы управления в ТЭК в нашей стране необходимо с учетом реформ, проводимых в соседних странах; для восстановления своих позиций в рамках развития уже интеграционных процессов необходимо создание Министерства энергетики КР для принятия решений на равных условиях на министерском уровне. В перспективе в проекте Концепции развития ТЭК до 2030 г. прогноз баланса электроэнергии показывает возможность экспорта в объеме 1,7 млрд кВт.ч при завершении проекта CASA-1000 и свыше 4 млрд кВт.ч ежегодно в ОЭС ЦА при сооружении Камбаратинской ГЭС-1, на электроэнергию которой и рассчитывает Узбекистан, для гарантированного получения водных ресурсов в летний период на нужды орошения в сельском хозяйстве. Для участия в работе общего электроэнергетического рынка ЕАЭС создается Кыргызский энергетический расчетный центр с централизованным диспетчерским управлением.

Применительно к задачам развития ТЭК и его составляющих фактор энергетической безопасности должен быть одним из основных критериев принятия решений, наряду с критериями экологичности, энергоэффективности, окупаемости инвестиций, производительности труда, надежности, производственной безопасности, качества продукции и др.

Достижение указанных ориентиров, повышение управляемости процессом развития энергетики требуют формирования основных составляющих государственной энергетической политики. Это, прежде всего, обеспечение эффективного пользования государственным фондом энергоресурсов, развитие внутренних топливно-энергетических рынков, формирование рационального баланса.

Реализация мер требует создания нормативно-правовой основы и принятия закона «Об энергетической безопасности». На основе законодательства должны быть определены исполнительные органы, ответственные за формирование нормативов энергетической безопасности, их мониторинг и регламент деятельности в данной сфере.

Для обеспечения энергетической безопасности необходимо осуществить модернизацию во многом морально устаревшей и физически изношенной технологической базы ТЭК и обеспечить воспроизводство его вырабатываемой ресурсной базы, а также изменение структуры потребления и размещения производства ТЭР. При этом предусматривается увеличение использования гидроэнергетических ресурсов.

Предотвращение и преодоление существующих и потенциальных угроз энергетической безопасности внутреннего и внешнего характера должно быть предметом постоянной заботы государственных и местных органов.

В то же время одним из необходимых условий эффективного обеспечения энергетической безопасности, своевременного предотвращения или ослабления со- 
ответствующих угроз являются постоянное отслеживание, оценка и анализ с позиций энергетической безопасности ситуации (существующей и ожидаемой в перспективе) в ТЭК и системах энергетики, сфере энергопотребления, экономики в целом.

Таким образом, конечной целью исследований в данном направлении должно стать формирование системы индикативных показателей, которые характеризуют состояние энергетической безопасности, предложений по нормативному регламентированию этих индикативных показателей, разработка плана первоочередных мер ее обеспечения и организация мониторинга.

\section{БИБЛИОГРАФИЧЕСКИЙ СПИСОК}

Асланян Г.С., Молодцов С.Д., Соловьянов АА. Роль государства в обеспечении энергетической безопасности. В кн.: Энергетическая политика России на рубеже веков: в 2 т. М.: Папирус ПРО, 2001, т. 2.

Баетов Б.И. Актуальные вопросы энергетической безопасности Кыргызской Республики. Бишкек: Инсанат, 2010.

Баетов Б.И., Архангельская А.В. Энергетические вопросы формирования «зеленой экономики» Кыргызской Республики. Журнал правовых и экономических исследований. Journal of Legal and Economic Studies, 2018, 1, 156-159.

Бушуев В.В. Энергетический потенциал и устойчивое развитие. М.: Энергия, 2006. c. 200 .

Быкова Е.В. Мониторинг индикаторов энергетической безопасности. Кишинев, 2008.

В Евразийской экономической комиссии предложили ускорить создание общего рынка газа в ЕАЭС, 9 OKТ 2018. TACC. URL: https://tass.ru/ekonomika/5652329/ (дата обращения: 29 мая 2019).

Гительман Л.Д., Ратников Б.Е. Энергетический бизнес. М.: Дело, 2006.

Гительман Л.Д., Ратников Б.Е. Эффективная энергокомпания: Экономика. Менеджмент. Реформирование. М.: Олимп-Бизнес, 2002.

Единый энергорынок Евразийского союза позволит создать новые рабочие места: Интервью министра по энергетике и инфраструктуре ЕЭК Эмиля Кайкиева, 2019. Евразийская экономическая комиссия. URL: http://www.eurasiancommission.org/ru/ nae/news/Pages/Forms/DispForm.aspx?ID=4818 (дата обращения: 29 мая 2019).

Иванов С.Б. Топливно-энергетический комплекс в системе национальной безопасности. Энергетическая политика, 2000, No. 1-2.

Касымова В.M. Энергетическая политика, энергобезопасность и энергоэффективность Кыргызской Республики. Бишкек: Барак-Элде, 2017.

Касымова В.М., Архангельская А.В., Куржумбаева Р.Б. Научные основы концепции государственной энергетической политики и стратегии развития топливноэнергетического комплекса Кыргызской Республики до 2030 года. Бишкек, 2017. 
Саркисян Т.С. Создание общих рынков энергетических ресурсов ЕАЭС: этапы и содержание. Известия Санкт-Петербургского государственного экономического университета, 2017, No. 1-1, 65-69.

Шамраев Н.Г., Троицкий А.А. Энергетическая безопасность России - важнейший фактор ее экономической безопасности. Энергетическая политика, 1996, No. 2.

Key world energy statistics 2018. International Energy Agency. URL: https://webstore. iea.org/key-world-energy-statistics-2018.

\section{REFERENCES}

Aslanyan, G.S., Molodtsov, S.D., Solovyanov, A.A. (2001). Rol gosudarstva v obespechenii energeticheskoy bezopasnosti [The role of the state in ensuring energy security]. In: Energeticheskaya politika Rossii na rubezhe vekov: v 2 t. (Russia's energy policy at the turn of the century: in 2 tons). M.: Papyrus PRO, Vol. 2.

Baetov, B.I. (2010). Aktualnye voprosy enrgeticheskoy bezopasnosti Kyrgyzskoy respubli$k i$ [Current issues of energy security of the Kyrgyz Republic]. Bishkek: Insanat.

Baetov, B.I., Arkhangelskaya, A.V. (2018). Energeticheskie voprosy formirovaniya zelenoy ekonomiki Kyrgyzskoy Respubliki [Energy issues of the formation of a "green economy" of the Kyrgyz Republic]. Zhurnal pravovyh i ekonomicheskih issledovanij [Journal of Legal and Economic Studies], no 1, 156-159.

Bushuev, V.V. (2006). Energeticheskiy potencial I ustoychivoe razvitie [Energy potential and sustainable development]. - Moscow: Energia.

Bykova, E.V. (2008). Monitoring indikatorov energeticheskoy bezopasnosti [Monitoring of energy security indicators]. Kishinev.

V Evrazijskoj ekonomicheskoj komissii predlozhili uskorit' sozdanie obshchego rynka gaza v EAES, 9 OKT 2018. [The Eurasian Economic Commission proposed to speed up the creation of a common gas market in the EAEU, 9 OCT 2018]. TASS. Available at: https://tass.ru/ekonomika/5652329/, (accessed 29 May 2019).

Gitelman, L.D., Ratnikov, B.E. (2006). Energeticheskiy biznes [Energy business]. M.: Delo.

Gitelman, L.D., Ratnikov, B.E. (2002). Effektivnaya energokompaniya: Ekonomika. Upravlenie. Reformirovanie. (Efficient power company: Economy. Management. Reforming). M.: Olimp-Business.

Edinyj energorynok Evrazijskogo soyuza pozvolit sozdat> novye rabochie mesta: Interv yu ministra po energetike i infrastrukture EEK Emilya Kajkieva, 2019. [The single power market of the Eurasian Union will create new jobs: Interview of the Minister of Energy and Infrastructure of the EEC Emil Kaikiev, 2019]. Evrazijskaya ekonomicheskaya komissiya [Eurasian Economic Commission]. Available at: http:// www.eurasiancommission.org/ru/nae/news/Pages/Forms/DispForm.aspx?ID=4818 (accessed 29 May 2019).

Ivanov, S.B. (2000). Toplivno-enrgeticheskiy kompleks v sisteme nacionalnoy bezopasnosti [Fuel and energy complex in the system of national security]. Energeticheskaya politika [Energy Policy], no 1-2. 
Kasymova, V.M. (2017). Energeticheskaya politika, energobezopasnost $i$ energoeffektivnost Kyrgyzskoy Respubliki [Energy policy, energy security and energy efficiency of the Kyrgyz Republic]. Bishkek: Barak-Elde.

Kasymova, V.M., Arhangel'skaya, A.V., Kurzhumbaeva, R.B. (2017). Nauchnye osnovy koncepcii gosudarstvennoj energeticheskoj politiki i strategii razvitiya toplivno-energeticheskogo kompleksa Kyrgyzskoj Respubliki do 2030 goda [Scientific basis for the concept of the state energy policy and strategy for the development of the fuel and energy complex of the Kyrgyz Republic until 2030]. Bishkek.

Sargsyan, T.S. (2017). Sozdanie obshih rynkov energeticheskih resursov EAES: etapy i soderjanie [Creation of common markets for energy resources of the EAEU: stages and content]. Izvestiya Sankt-Peterburgskogo gosudarstvennogo ekonomicheskogo universiteta [Journal of St. Petersburg State University of Economics], no 1-1 (p. 65-69).

Shamraev, N.G., Troitsky, A.A. (1996). Energeticheskaya bezopasnost Rossii — vajneyshiy factor ee ekonomicheskoy bezopasnosti [Energy security of Russia - the most important factor in its economic security]. Energeticheskaya politika [Energy policy], no 2.

Key world energy statistics 2018. International Energy Agency. Available at: : https:// webstore.iea.org/key-world-energy-statistics-2018. 